\title{
Effect of Added Mass to Wrist on Gait Parameters in Stroke Patients
}

\author{
KwANG-JUn LeE ${ }^{1)}$, TAEK-OH Kim ${ }^{1)}$, Won-Gyu YoO $^{2)}$ \\ 1) Department of Physical Therapy, Graduate School, Inje University \\ 2) Department of Physical Therapy, College of Biomedical Science and Engineering, Inje University \\ and Elderly Life Redesign Institute: 607 Obangdong, Gimhae, Gyeongsangnam-do 621-749, Republic \\ of Korea.TEL+82 55-320-3994; FAX:+82 55-329-1678; E-mail: won7y@inje.ac.kr
}

\begin{abstract}
Purpose] The purpose of this study was to compare the gait parameters of stroke patients with added mass to the wrist during walking. [Subjects] For this study, we recruited 16 stroke survivors as voluntary participants. [Methods] We measured the gait parameters under 3 conditions (without added mass, with a $1.0 \mathrm{~kg}$ load, and with a $1.8 \mathrm{~kg}$ load). [Results] The gait parameters of velocity, cadence, and stride length on the affected side were significantly increased under the $1.0 \mathrm{~kg}$ condition, and the no load and $1.8 \mathrm{~kg}$ conditions resulted in no significant change. [Conclusion] The findings of this study suggest that applying the optimal load to the less affected upper limb may benefit people with hemiplegic gait and could improve the efficiency of gait performance.

Key words: GAITRite, Hemiplegic gait, Stroke
\end{abstract}

(This article was submitted Jun. 4, 2012, and was accepted Jun. 28, 2012)

\section{INTRODUCTION}

Stroke induces long-term disability including motor and sensory deficits and decreased cognitive functions ${ }^{1)}$. Hemiplegic gait has the following characteristics; decreased gait velocity, reduced joint movement ability, abnormal muscle tone, asymmetry stride length, and increased energy consumption $^{2,3)}$. Arm swing is an essential component of gait, and lack of arm swing increases the metabolic cost of walking ${ }^{4,5)}$. Upper limb movement has a less important role than lower limb movement during walking, but it is not passive motion, and reciprocal arm swing has a very important role during the gait cycle ${ }^{6,7)}$. Cavagna et al. ${ }^{8)}$ reported that load on an upper limb changed gait parameters during the swing phase of stepping. In addition, added mass showed produced changes in muscle activities in the loaded arm and there is a strong relationship between upper and lower limbs during walking ${ }^{9)}$. Many studies have analyzed the effect of load on an arm during walking with healthy subjects, but no study has reported the effect of loading of the arm on hemiplegic gait. The purpose of this study was to compare the gait parameters of stroke patients with mass added to the wrist during walking.

\section{SUBJECTS AND METHODS}

Sixteen patients with hemiplegic stroke were enrolled from D medical center located in Busan, Korea. The subject's general characteristics as follow: there are were six men and five women, and the paretic side was the left for four subjects and the right for seven subjects. The Brunnstrom stage was 3 for five subjects, 4 for eight subjects and 5 for three subjects.
Their average age, height and weight were $55.7 \pm 8.4$ years, $163.8 \pm 12.3 \mathrm{~cm}$ and $62.84 \pm 10.1 \mathrm{~kg}$, respectively. The average Mini Mental State Examination-Korea score was $26.7 \pm 1.4$. The inclusion criteria for the experiment were as follow: 1) first and single unilateral stroke, 2) ability to walk $20 \mathrm{~m}$ independently without an assistive device, 3) ability to walk $30 \mathrm{~min}$ independently without an assistive device, 4) score above 24 in the MMSE-K and 5) ability to communicate with evaluators. A GAITRite system (CIR Systems, Easton, PA, USA) was used to measure the gait parameters and is a highly valid and reliable tool. GAITRite electrical walkway contains six sensor pads encapsulated in a roll-up carpet to produce an active area that is $61 \mathrm{~cm}$ wide and $366 \mathrm{~cm}$ long. The carpet consisted of a total of 13,824 sensors. The sensors detected the foot surface during walking, and then the GAITRite software calculated and displayed the gait parameters. The subject walked on the GAITRite pathway under the following three conditions: no mass, $1.0 \mathrm{~kg}$ applied to the wrist, and $1.8 \mathrm{~kg}$ applied to the wrist. The mass was applied in the form of a bracelet with a Velcro strap filled with $1.0 \mathrm{~kg}$ or $1.8 \mathrm{~kg}$ of sand ${ }^{9)}$. Arm swing as counterbalances the role to opposite leg and pelvis, and a smooth gait can be created by controlled arm swing ${ }^{7)}$. In this experiment, the mass was applied as strips around the wrist on the less affected side of the subject, and the tester asked the subject to walk at his/her self-selected speed from the start line to the finish line $(10 \mathrm{~m})$. SPSS ver. 18.0 was used for statistical analysis in this study. The effect of different conditions (no mass, $1.0 \mathrm{~kg}$ and $1.8 \mathrm{~kg}$ ) on the gait parameters was analyzed by using a repeated-measures one-way ANOVA. The statistical significance level was set at 0.05 . 
Table 1. Comparison of gait parameters under the 3 conditions

\begin{tabular}{lccc}
\hline Gait parameters & None & $1.0 \mathrm{~kg}$ & \multicolumn{1}{c}{$1.8 \mathrm{~kg}$} \\
\hline Velocity $(\mathrm{m} / \mathrm{s})$ & $60.4 \pm 29.8$ & $71.6 \pm 29.9^{*}$ & $62.3 \pm 32.5$ \\
Cadence $(\mathrm{steps} / \mathrm{min})$ & $86.8 \pm 20.5$ & $93.0 \pm 18.5^{*}$ & $87.30 \pm 22.0$ \\
Affected side stride length $(\mathrm{cm})$ & $79.8 \pm 23.1$ & $89.2 \pm 22.4^{*}$ & $82.37 \pm 24.7$ \\
Less affected side stride length $(\mathrm{cm})$ & $79.7 \pm 22.6$ & $83.5 \pm 23.2$ & $82.00 \pm 24.5$ \\
\hline
\end{tabular}

${ }^{*} \mathrm{p}<0.05$

\section{RESULTS}

The gait velocity and cadence of the participants increased significantly under the $1.0 \mathrm{~kg}$ condition compared with the no mass and $1.8 \mathrm{~kg}$ conditions. Under the $1.0 \mathrm{~kg}$ mass condition, the stride length of the affected side was significantly different from those under the no mass and $1.8 \mathrm{~kg}$ conditions (Table 1).

\section{DISCUSSION}

The main purpose of this study was to investigate the effect of the adding mass to the wrist on the gait performance of stroke patients. This study found several significant differences: the velocity, cadence and stride length on the affected side were increased under the $1.0 \mathrm{~kg}$ loaded condition. The results of this study showed increases in gait velocity, cadence, and stride length on the affected side under the $1.0 \mathrm{~kg}$ loaded condition. Increase of gait velocity is an important goal of hemiplegic gait patients after a stroke ${ }^{1,2)}$. Arm swing during walking is often compared with pendulum movement ${ }^{7)}$, and it appear that the $1.0 \mathrm{~kg}$ load on the wrist in this study added propulsion via pendulum moment during arm swing. This increased arm swing might have increased movement of the lower limb on the contralateral side to maintain coordination of upper and lower limb movement ${ }^{10)}$. Haung and Ferris ${ }^{11)}$ also reported that it is more efficient during rhythmic movement for the upper limbs to move together with the contralateral lower limbs. Adding mass to the less affected side might cause arm swing to increase. The added mass improve the potential and kinetic energy of the center of mass via pendular movement. Therefore, the increases energy transduction, particularly during the swing phase of the step. When walking, subjects need the forward momentum provided by arm swing to counterbalance the downward momentum of the center of mass ${ }^{4,5)}$. The counterbalancing action might provide gait stability that enhances the walking ${ }^{6)}$. In a previous study, increased arm swing reduced lateral sway and increased for-aft and ground reaction force ${ }^{6}$. In the present study, $1.8 \mathrm{~kg}$ was less effective than $1.0 \mathrm{~kg}$ weight. During arm swing, deltoid muscle activity particularly increased during retraction, since retraction of the arm with $1.0 \mathrm{~kg}$ weight attached might increase the potential energy of arm swing by pendulum movement ${ }^{12)}$. We suggest that $1.0 \mathrm{~kg}$ might be the optimal load for the subjects in this study. Adding the optimal mass to the wrist might improve gait parameters by enhancing arm swing. This study had several limitations. The experiment utilized a small sample and did not measure any muscle activities. Further study with a large sample size and measurement of the biomechanical parameters and electromyography is needed.

\section{ACKNOWLEDGEMENTS}

This research was supported by Basic Science Research Program through the National Research Foundation of Korea (NRF) funded by the Ministry of Education, Science and Technology (No. 2012001058).

\section{REFERENCES}

1) Ward NS, Cohen LG: Mechanism underlying recovery of motor function after stroke. Arch Neurol, 2004, 61: 1844-1848. [Medline] [CrossRef]

2) Ng SS, Hui-Chan CW: The timed 'up \& go' test: its reliability and association with lower limb impairments and locomotor capacities in people with chronic stroke. Arch Phys Med Rehabil, 2005, 86: 1641. [Medline] [CrossRef]

3) Thaut $\mathrm{MH}$, Mclntosh G, Rice R: Rhythmic facilitation of gait training in hemiparetic stroke rehabilitation. J Neurol Sci, 1997, 151: 207-212. [Medline] [CrossRef]

4) Collins SH, Adamczyk PG, Kuo AD: Dynamic arm swinging in human walking. Proc Biol Sci, 2009, 276: 3679-3688. [Medline] [CrossRef]

5) Umberger BR: Effects of suppressing arm swing on kinematics, kinetics, and energetics of human walking. J Biomech, 2008, 41: 2575-2580. [Medline] [CrossRef]

6) Lulić TJ, Susić A, Kodvanj J: Effects of arm swing on mechanical parameters of human gait. Coll Antropol, 2008, 32: 869-873. [Medline]

7) Jackson KM, Joseph J, Wyard SJ: A mathematical model of arm swing during human locomotion. J Biomech, 1978, 11: 277-289. [Medline] [CrossRef]

8) Cavagna GA, Willems PA, Legramandi MA, et al.: Pendular energy transduction within the step in human walking. J Exp Biol, 2002, 205: 3413-3422. [Medline]

9) Donker SF, Mulder T, Nienhuis B, et al.: Adaptations in arm movements for added mass to wrist or ankle during walking. Exp Brain Res, 2002, 146: 26-31. [Medline] [CrossRef]

10) Yizhar $Z$, Boulos $S$, Inbar $O$, et al.: The effect of restricted arm swing on energy expenditure in healthy men. Int J Rehabil Res, 2009, 32: 115-123. [Medline] [CrossRef]

11) Huang HJ, Ferris DP: Upper and lower limb muscle activation is bidirectionally and ipsilaterally coupled. Med Sci Sports Exerc, 2009, 41: 1778-1789. [Medline] [CrossRef]

12) Ballesteros ML, Buchtal F, Rosenfalck R: The pattern of muscular activity during the arm swing of natural walking. Acta Physiol Scand, 1965, 63: 296-310. [Medline] [CrossRef] 